\title{
To Resect or Not to Resect Extrahepatic Bile Duct in Gallbladder Cancer?
}

\author{
Paschalis Gavriilidiss ${ }^{\mathrm{a}, \mathrm{d}}$, Alan Askari ${ }^{\mathrm{b}}$, Daniel Azoulay ${ }^{\mathrm{a}, \mathrm{c}}$
}

\begin{abstract}
The indications for and limitations of extrahepatic bile duct resection (EHBDR) in the context of gallbladder (GB) cancer are unclear. The purpose of this review was to examine the current literature to determine the impact of EHBDR on loco-regional recurrence and survival in GB cancer. The EMBASE and Medline databases were searched up to February 2016 using the terms: extrahepatic bile duct resection and gallbladder cancer. Studies published in the last 20 years were eligible for inclusion. Given the heterogeneity of the population and the study methodologies employed, qualitative data synthesis in the form of meta-analysis was deemed implausible. Twenty-four studies fulfilled the inclusion criteria. The selected studies include 6,722 (55\%) EHBDRs in a total of $12,251 \mathrm{~GB}$ cancer operations. The 25 studies were categorized into seven groups: 1) cancer survival all stages; 2) hepatoduodenal ligament invasion; 3) outcome in EHBDR and EHBDNR; 4) pT1b tumors; 5) pT2 tumors; 6) pT3/T4 tumors; and 7) incidental GB cancer. Radical cholecystectomy with EHBDR should be used as a standard operation for tumors involving the neck or the cystic duct of the GB (either macroscopically or microscopically). In all other cases, operative strategy should be individualized to the patient.
\end{abstract}

Keywords: Extrahepatic bile duct resection; Gallbladder cancer

\section{Introduction}

The era of radical operations for gallbladder (GB) cancer dawned in 1954, when Glenn and Hays proposed radical chol-

Manuscript accepted for publication October 25, 2016

aDepartment of Hepato-Pancreato-Biliary Surgery and Liver Transplantation, Henri Mondor University Hospital, 51 Avenue du Marechal de Lattre de Tassigny, 94010 Creteil, France

${ }^{b}$ Department of Surgery, Ipswich Hospital, NHS Trust Ipswich, Heath Rd IP4 5PD, UK

'INSERM U 955, Creteil, France

${ }^{\mathrm{d} C}$ Corresponding Author: Paschalis Gavriilidis, Department of Hepato-Pancreato-Biliary Surgery and Liver Transplantation Henri Mondor University Hospital, 51 avenue du Marechal de Lattre de Tassigny, 94010 Creteil, France. Email: pgav7461@yahoo.com

doi: https://doi.org/10.14740/jocmr2804w ecystectomy for managing patients with GB cancer [1]. Soon after, Pack et al reported the management of three cases with right hepatic lobectomy (right trisectionectomy according to the Brisbane terminology) [2], of which one patient survived more than 2 years [3]. Today, Glenn's radical cholecystectomy is recommended by the National Comprehensive Cancer Network (NCCN) for GB cancers that are stage T1b or greater [4].

Further operative strategies were developed in the 1980s, when Shirai et al reported the successful management of five patients with advanced GB cancer with hepatopancreatoduodenectomy (HPD) [5]. The Japanese team proposed a combination of radical cholecystectomy (comprising of cholecystectomy and a $2 \mathrm{~cm}$ margin of non-neoplastic liver parenchyma around the GB), choledochectomy and hepatoduodenal lymphadenectomy in an en bloc fashion as the treatment of choice of the GB cancer [6].

However it is unclear as to what the role of extrahepatic bile duct resection (EHBDR) is, in the management of GB cancer. The aim of this review was to evaluate the necessity of choledochectomy in GB cancer surgery and to identify the principles of operative strategy to ensure best oncological recurrence and survival outcome.

\section{Methods}

\section{Study selection}

Using the terms "extrahepatic bile duct(s)", "resection" and "gallbladder neoplasms" (or "gallbladder cancer"), we performed a systematic review of the literature in Medline and EMBASE databases searching for studies published in the last 20 years. The literature search was conducted in February 2016 by two independent reviewers (PG and DA). Reference lists of the pertinent articles were manually investigated to find additional articles.

\section{Data review extraction}

After independent evaluation of the studies by PG and DA, the following data were extracted: name of authors, data design, number of patients included in the resected and non-resected cohort, age, gender, EHBDR, hepatoduodenal ligament (HDL) 
Table 1. Characteristics of Included Studies

\begin{tabular}{|c|c|c|c|c|c|c|}
\hline $\begin{array}{l}\text { Author, year, country, } \\
\text { study type }\end{array}$ & $\begin{array}{l}\text { Number of } \\
\text { patients (n) }\end{array}$ & Age (range) & Gender $\mathbf{M} / \mathbf{F}$ & Definitions & EHBDR, n (\%) & 5-years OS \\
\hline $\begin{array}{l}\text { Pandey et al [17] } \\
2015 \\
\text { India } \\
\text { RA }\end{array}$ & 17 & $51(35-62)$ & $5 / 12$ & AJCC seventh & $17(100)$ & 26 months \\
\hline $\begin{array}{l}\text { He et al [10] } \\
2015 \\
\text { China } \\
\text { Telephone FU RA }\end{array}$ & 152 & $68(29-89)$ & $61 / 91$ & AJCC seventh & $\begin{array}{l}57 \text { total } \\
\text { St I }=6(33) \\
\text { St II }=9(36) \\
\text { St III }=42(55)\end{array}$ & $26 \%$ \\
\hline $\begin{array}{l}\text { Hwang et al [28] } \\
2015 \\
\text { Korea } \\
\text { RA }\end{array}$ & 103 & $61.6 \pm 10(35-84)$ & $36 / 67$ & AJCC seventh & $28(28)$ & $\begin{array}{l}\mathrm{T} 3 \mathrm{~N} 0=58 \% \\
\mathrm{~T} 1 \mathrm{~N} 1=15 \% \\
\mathrm{~T} 2 \mathrm{~N} 1=29 \% \\
\mathrm{~T} 3 \mathrm{~N} 1=5 \%\end{array}$ \\
\hline $\begin{array}{l}\text { Choi et al [19] } \\
2013 \\
\text { Korea } \\
\text { RA }\end{array}$ & 71 & $64(22-82)$ & $32 / 39$ & AJCC seventh & $30(42.25)$ & $\begin{array}{l}\text { R pT2 }=56 \% \\
\text { NR pT2 }=76 \% \\
\text { R pT3 }=39 \% \\
\text { NR pT3 }=54 \%\end{array}$ \\
\hline $\begin{array}{l}\text { Gwark et al [23] } \\
2012 \\
\text { Korea } \\
\text { RA }\end{array}$ & 48 & $63 \pm 83.3$ & $23 / 25$ & NR & $16(33)$ & $62 \%$ \\
\hline $\begin{array}{l}\text { Shirai et al [25] } \\
2012 \\
\text { Japan } \\
\text { RA }\end{array}$ & 145 & $66.5(43-84)$ & 42,430 & AJCC seventh & $52(36)$ & $65 \%$ \\
\hline $\begin{array}{l}\text { Nasu et al [14] } \\
2012 \\
\text { Japan } \\
\text { RA }\end{array}$ & 38 & $71(58-83)$ & $13 / 14$ & AJCC seventh & $27(71)$ & $34 \%$ \\
\hline $\begin{array}{l}\text { Nishio et al [15] } \\
2011 \\
\text { Japan } \\
\text { RA }\end{array}$ & 100 & $63(37-79)$ & $30 / 43$ & AJCC seventh & $87(87)$ & $36 \%$ \\
\hline $\begin{array}{l}\text { Lim et al [30] } \\
2012 \\
\text { Korea } \\
\text { RA }\end{array}$ & 10 & $58 \pm 10.4(27-72)$ & AJCC sixth & $10(100)$ & & $10 \%$ \\
\hline $\begin{array}{l}\text { Agarwal et al [16] } \\
2007 \\
\text { India } \\
\text { RA }\end{array}$ & 14 & $49(21-68)$ & 42,677 & AJCC sixth & $14(100)$ & $\begin{array}{l}\text { OS: not given } \\
\text { DFS: } 24 \text { months }\end{array}$ \\
\hline $\begin{array}{l}\text { Fuks et al }[31] \\
2011 \\
\text { France } \\
\text { RA }\end{array}$ & 218 & $64(31-88)$ & $67-151$ & AJCC seventh & $63(43)$ & $41 \%$ \\
\hline $\begin{array}{l}\text { Araida et al [18] } \\
2009 \\
\text { Japan } \\
\text { RQS multicentre study }\end{array}$ & 4,243 & $\begin{array}{l}\mathrm{EHBDNR}=68 \pm 12.5 \\
\mathrm{EHBDR}=65.2 \pm 11.2\end{array}$ & $\begin{array}{l}\mathrm{BDNR}= \\
160 / 233 ; \mathrm{BDR} \\
=67 / 127\end{array}$ & $\begin{array}{l}\text { JSBS fifth } \\
\text { edition }\end{array}$ & $\begin{array}{l}2,897(68) 838 \\
\text { pT2,3,4 w/o } \\
\text { HDL and cystic } \\
\text { duct invasion }\end{array}$ & $\begin{array}{l}R=75 \% \\
N R=65 \%\end{array}$ \\
\hline $\begin{array}{l}\text { Kohya et al }[22] \\
2010 \\
\text { Japan } \\
\text { RA }\end{array}$ & 84 & $67.6(45-87)$ & $27-57$ & AJCC sixth & $30(36)$ & $\begin{array}{l}100 \% \text { in ss } \min \text { and } \\
\text { med, ssmas }=59.7 \%\end{array}$ \\
\hline $\begin{array}{l}\text { Kayahara et al [7] } \\
2008 \\
\text { Japan } \\
\text { Retrospective survey }\end{array}$ & 4,424 & $\begin{array}{l}\text { Cholelithiasis }=66.9 \\
\text { APBDJ }=58.6 \\
\text { De novo }=65.8\end{array}$ & $1,608 \mathrm{M} / 2,816$ & AJCC fifth & $2,141(48)$ & $\begin{array}{l}<60 \text { years } 34 \%-> \\
60 \text { years } 28 \%\end{array}$ \\
\hline
\end{tabular}


Table 1. Characteristics of Included Studies - (continued)

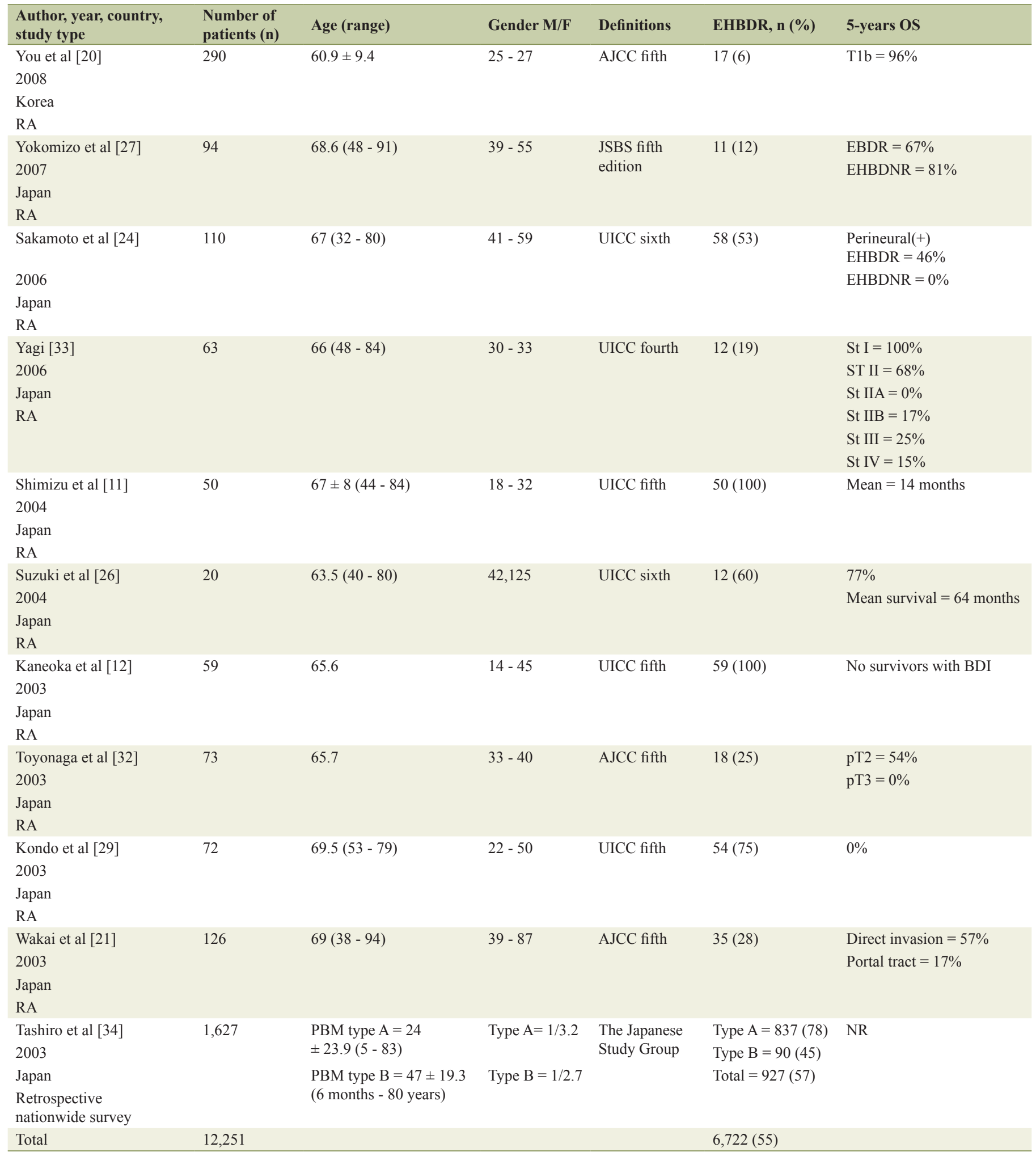

AJCC: American Joint Committee on Cancer; APBDJ: Anomalous pancreatobiliary duct junction; BDI: bile duct invasion; EHBDR: extrahepatic bile duct resection; DFS: disease free survival; EHBDNR: extrahepatic bile duct non-resection; JSBS: Japanese Society of Biliary Surgery; HDL: hepatoduodenal ligament; PBM: pancreatobiliary maljunction; UICC: union for international cancer control; RA: retrospective analysis; R: resected; NR: non-resected; St: stage; SS: subserosal; w/o: without. 
invasion, hepatic bed invasion, N1/2 status, perineural invasion, R0 status, TNM stage, median follow-up, disease-free survival, and 5-year survival.

\section{Definitions}

Three classifications were used for staging tumors: the American Joint Committee on Cancer manual (AJCC) fifth, sixth, or seventh edition, the Japanese Society of Biliary Surgery (JSBS) fifth edition and the Union for International Cancer Control (UICC) fifth and sixth edition. Glenn's radical cholecystectomy or simply radical cholecystectomy comprises of cholecystectomy, a $2 \mathrm{~cm}$ resection margin of non-neoplastic liver parenchyma around the GB and hepatoduodenal lymphadenectomy. Extended radical cholecystectomy comprises of cholecystectomy, a $2 \mathrm{~cm}$ or greater resection margin of nonneoplastic liver parenchyma, resection of the common bile duct (CBD) and systematic regional lymphadenectomy that comprises of cystic, pericholedochal, hilar, common hepatic, coeliac, retropancreatic and superoposterior pancreatoduodenal lymph nodes.

\section{Results}

Given the heterogeneity of both the populations as well as the differences in study methodology, qualitative data analyses in the form of meta-analysis were impossible. Therefore, the finding of each study is presented separately.

\section{Study characteristics}

A total of 450 studies were found in the searched databases. After review of the full manuscript, 24 articles met the inclusion criteria and were selected for this. Across these 25 studies, a total of 12,251 patients underwent surgery for GB cancer, of which 6,722 (55\%) had EHBDR. The 25 studies were categorized into seven groups (Tables 1, 2, Fig. 1) [7-35].

\section{Cancer survival: all stages}

Kayahara et al selected 4,424 cases from 4,770 patients, who fulfilled both the JSBS and AJCC fifth edition staging criteria [7]. The AJCC fifth edition defines $\mathrm{pN} 2$ using the same criteria as the JSBS [7]. Multivariate analysis demonstrated that tumor stage was the strongest prognostic factor for survival. In this study, the survival rate was $83 \%$ for stage I, $70 \%$ for stage II, $45 \%$ for stage III, $23 \%$ for stage IVa, and $9 \%$ for stage IVb. Conversely, in the European and North American studies the reported 5-year survival rate ranged from $2.7 \%$ to $15 \%[8,9]$. EHBDR and liver bed resection had a positive effect on overall survival only in patients of stage II and III.

One study by $\mathrm{He}$ and colleagues recommended simple cholecystectomy for stage 0 and I and a radical cholecystectomy for stage II and III. In this study, high proportions of patients underwent radical cholecystectomy, in stage II $43 \%$, stage III $55 \%$ and stage IVAa $79.2 \%$ [10].

\section{HDL invasion}

Shimizu and colleagues studied 50 surgical specimens and defined four types of invasion of the HDL, namely, type I: direct extramural spread; type II: continuous intramural spread; type III: distant spread separated from the primary tumor; and type IV: spread of cancer cells from metastatic lymph nodes. The stage distribution of the 50 patients was IB $(26 \%)$ in 13 patients, IIA (4\%) in two patients, IIB (48\%) in 24 patients and IV $(22 \%)$ in 11 patients. Of these 50 patients, $30(60 \%)$ had HDL invasion (type I: $n=9$; type II: $n=4$; type III: $n=5$; and type IV: $n=4)$. From the 50 patients who underwent EHBDR, the 17 with HDL invasion type II, III and IV had a significantly better survival than 13 patients with type I [11].

Kaneoka and colleagues defined HDL invasion as an equation with two components, namely, lymph node involvement (LNI) and bile duct invasion (BDI). Three patterns of histologic invasion of BDI have been defined: direct, lymphatic and/or venous, and perineural. The recurrence rate was $52 \%$, $28 \%$, and $84 \%$ for direct, lymphatic/venous, and perineural invasion, respectively. All cases with BDI demonstrated stenosis of the CBD. In contrast, only $10 \%$ of patients $(n=4 / 40)$ with LNI demonstrated stenosis. Involvement of both BDI and LNI was associated with a lower rate of $\mathrm{R} 0$ resection. $\mathrm{In}_{\mathrm{LNI}}^{+} / \mathrm{BDI}^{+}$ tumors, the rate of R0 resection was $28 \%$. This rate increased to $75 \%$ in $\mathrm{LNI}^{-} / \mathrm{BDI}^{-}$tumors. Similarly, perineural invasion was one of the most frequent causes preventing R0 excision. Tumors that were $\mathrm{LNI}^{-} / \mathrm{BDI}^{-}$were also associated with a more favorable 3-year survival rate $\left(65.6 \%\right.$ in $\mathrm{LNI}^{-} / \mathrm{BDI}^{-}$compared with $5.9 \%$ in $\left.\mathrm{LNI}^{+} / \mathrm{BDI}^{+}\right)$. The authors concluded that radical interventions may benefit only patients with $\mathrm{LNI}^{+} / \mathrm{BDI}^{-}[12]$.

However, LNI and BDI may not be the only way to quantify GB cancer spread. In an effort to devise a new classification system, Yokoyama et al, based on the concept of the geometric center of the neoplasia, proposed subdividing cystic duct cancers into two types; hepatic hilum $(\mathrm{HH})$ and cystic confluence (CC). In this study, the authors found that obstructive jaundice, perineural and microscopic vascular invasions were more common in the HH than in the CC type. Similarly, overall survival was much lower in the HH type (median: 11.9 months, CI: 9.3 - 14.6) compared with the CC type (45.8 months, CI: 7.2 - 84.3) [13].

Nasu and colleagues compared the postoperative survival of patients with GB cancer invading the $\mathrm{HH}$ against those with hilar cholangiocarcinoma. He achieved a 93\% R0 resection for hilar GB cancer and $89 \%$ for hilar cholangiocarcinoma. Morbidity was $67 \%$ and $45 \%$, respectively and mortality was $4 \%$ and $3 \%$, respectively. In case of invasion of the portal bifurcation, a "non-touch" technique was used. The operation of choice was extended right hepatectomy and EHBDR. The 3 -and 5-year survival rates were $43 \%$ and $24 \%$ in GB cancer, and for hilar cholangiocarcinoma $58 \%$ and $38 \%$, respectively [14].

Nishio et al studied 100 patients with pT3/4 pN0/N1, M0 subdivided into CBD invasion positive and negative. Preop- 
Table 2. Main Findings in Each of the Topics in Gallbladder Cancer

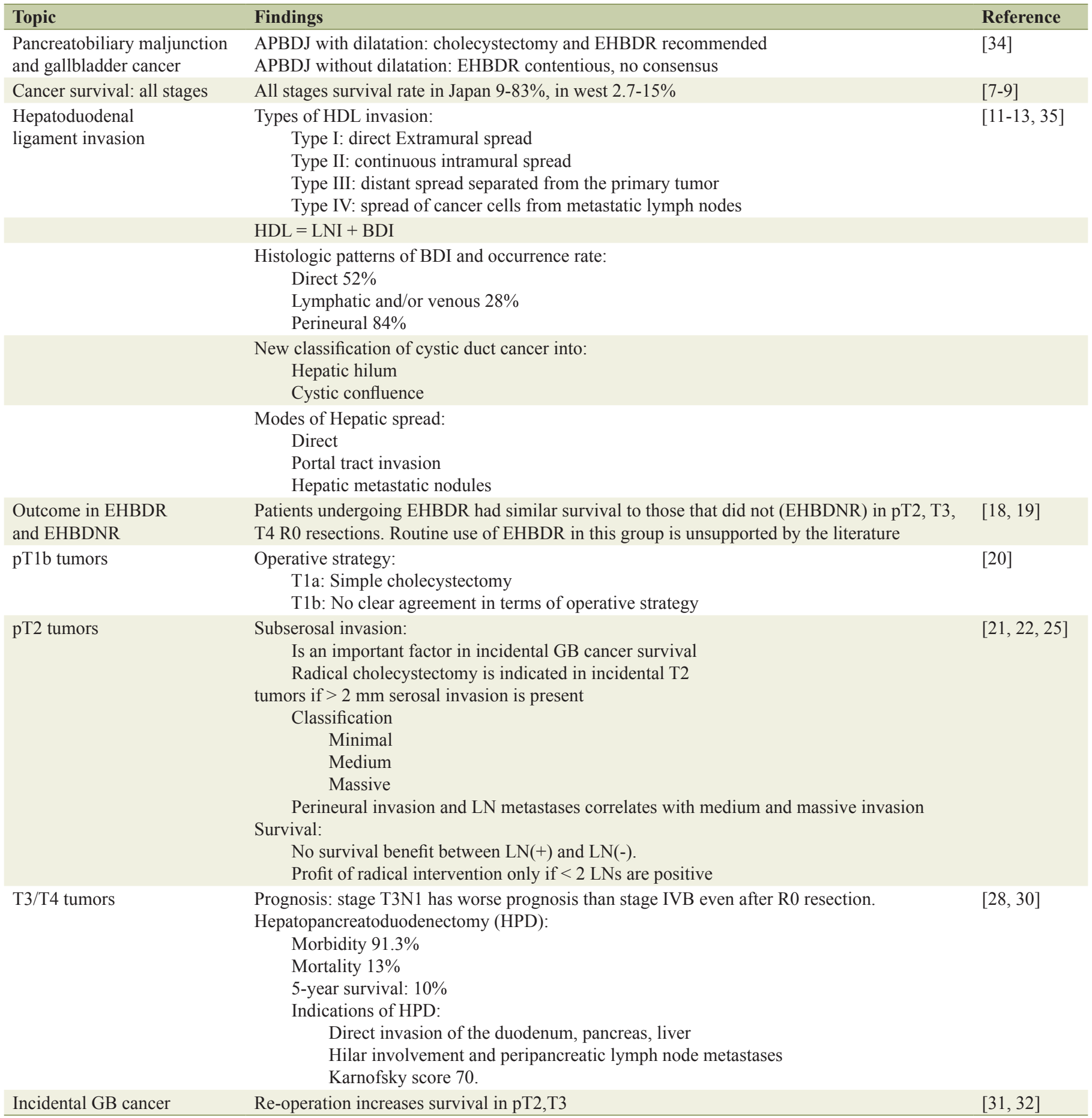

erative jaundice was reported in $4 \%$ of patients $(n=1)$ in the non-invaded cohort in contrast to $78 \%(n=58)$ of CBD invaded patients. Over half of the non-invaded patients $(52 \%, n$ $=14)$ underwent EHBDR, whereas $100 \%(n=73)$ invaded patients all underwent EHBDR. Portal resection was performed in two $(7 \%)$ of patients with non-invasion, but in $26(36 \%)$ of those with invasion.
Interestingly, microscopic invasion of the liver parenchyma was less frequent in patients with BDI, 26 of $73(36 \%)$, compared to patients with no invasion, 23 (85\%). R0 resection was achieved in $61 / 100$ patients. From this cohort, those who underwent concomitant resection of the adjacent organ had a 5-year survival of $16 \%$ and a median survival time of 0.8 years. However, those who did not undergo concomitant resec- 


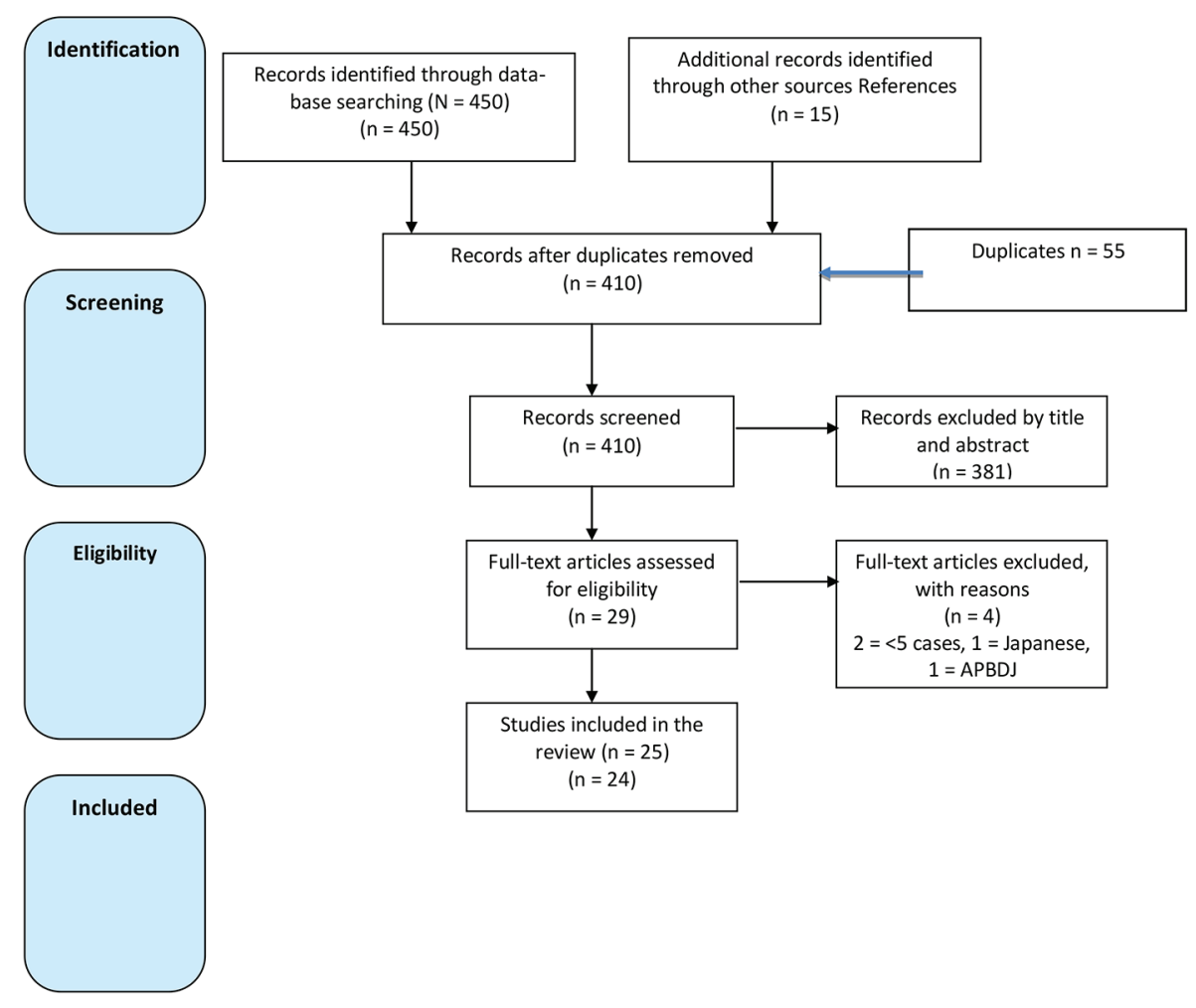

Figure 1. Flow diagram of selected studies.

tion had a 5 -year survival of $36 \%$ and a median survival time of 3.8 years. Eleven patients survived more than 5 years [15].

Agarwal et al reported a resectability rate of $27.5 \%$ amongst patients with obstructive jaundice. Mortality was $7.1 \%$ and morbidity was $50.0 \%$. The median survival time was 26 months (range: 2 - 62 months). Seven patients survived more than 2 years [16]. Pandey et al reported 17 patients who underwent radical cholecystectomy and EHBDR; all had R0 resection. Microscopic hepatic infiltration was observed in $47.0 \%(8 / 17)$ of patients and CBD invasion in $76.5 \%(13 / 17)$ of patients. Median overall survival was 26 months $(95 \% \mathrm{CI}$ : 7.7 - 44.2 months) [17].

\section{Outcome in EHBDR and EHBDNR}

Araida et al compared the survival of patients who underwent EHBDR with those who did not (EHBDNR). In this large national study of 114 Japanese institutions, a total of 4,243 patients underwent surgical treatment for GB cancer over a period of 9 years. EHBDR was performed in 2,897 (68.27\%) patients and $\mathrm{R} 0$ resection was achieved in 1,443 (49.81\%) of the total EHBDRs. The authors excluded patients with pT1 tumors and those with cystic duct invasion, leaving a total of 838 patients who had R0 resection for pT2, T3, T4 cancer without HDL to be included in the final analysis. There was no significant difference between the resected and preserved cases regarding the local and overall recurrence. Moreover, between the two cohorts, the 5-year cumulative survival rate was similar [18].
Other authors have reported similar findings. Choi and colleagues from Korea found lymphovascular invasion and lymph node metastases to be significant independent prognostic factors for overall survival in patients with $\mathrm{R} 0$ resection but they reported no statistical differences in survival between groups with resected and those with preserved CBDs [19].

\section{pT1b tumors}

The effect of T staging was studied by You and colleagues in which they compared oncological outcomes in 27 (52\%) patients with T1a and $25(48 \%)$ patients with T1b. All the T1a patients were treated with simple cholecystectomy. However, $17(32.7 \%)$ patients of the T1b group underwent radical cholecystectomy including HDL dissection CBD resection, bisegmentectomy $4 \mathrm{~b}+5$, or pancreatoduodenectomy. The overall survival was $96.3 \%$ in T1a and $96 \%$ in T1b. Metastatic rate and loco-regional recurrence was not different. During a median follow-up of 37 months, two (3.8\%) patients died, one from the T1a and one from the T1b group [20].

\section{pT2 tumors}

Wakai and colleagues studied 126 patients with pT2 tumors. They focused on 75 unapparent tumors to find which patients may benefit from radical interventions. In all surgical specimens, the depth of invasion was measured and the patients 
were categorized into two groups: those with tumors of $>2$ $\mathrm{mm}$ and $<2 \mathrm{~mm}$ of invasion. Sixty-six of the 126 patients $(52 \%)$ had a depth of invasion $>2 \mathrm{~mm}$. In both groups, those with apparent and unapparent tumors, the outcome was better for the cohort of patients with depth of invasion $>2 \mathrm{~mm}$ [21].

Further work into subserosal invasion has been carried out by Kohya and colleagues. In this study, T2 tumors with subserosal invasion were categorized into three distinct groups: minimal, medium and massive subserosal intrusion. Pathological factors including hepatic infiltration, lymphatic invasion, lymph node metastasis and perineural invasion were studied in each group. In the group with minimal subserosal invasion, overall survival was satisfactory, without the need for EHBDR. In the cohort with medium subserosal invasion pathological factors of perineural invasion, the overall survival rate in those with lymph node metastasis, hepatic infiltration and lymphatic invasion was $10 \%, 30 \%, 50 \%$, and $60 \%$, respectively. All pathological factors were expressed at high rates in the cohort with massive subserosal invasion. Based on these findings, the authors recommended partial hepatectomy and EHBDR in patients with medium and massive subserosal invasion [22].

In a study of 48 patients with T2N0 and R0 resection, Gwark and colleagues compared survival between patients who underwent EHBDR (33\% of the population, 16/48) and those who did not. The authors concluded that they found no difference in 3-year survival between the EHBDR and EHBDNR groups ( $72 \%$ for the EHBDR and $69.2 \%$ for the EHBDNR) [23]. Further studies by Sakamato and colleagues explored the role of EHBDR in patients with lymph node metastases and perineural invasion. EHBDR only demonstrated a survival benefit in patients with perineurial invasion but not in patients with nodal metastases [24].

Over a 24-year period, Shirai and colleagues performed 145 radical operations for GB cancer, of which $36 \%(52 / 145)$ were radical cholecystectomies including en bloc resection of the GB with its bed fossa, resection of the CBD and dissection of the lymph nodes of the first and second echelon. In the three patients $(6 \%, 3 / 52)$ with T1 tumors, all of the lymph nodes were free from metastases. However, in the remaining patients who had T2 tumors and greater, the rate of metastases was $47 \%(23 / 52)$. In this cohort of 23 patients, 10 patients $(10 / 23$, $43 \%$ ) who had 1 - 2 positive lymph nodes survived more than 5 years. The authors concluded that radical cholecystectomy is of a survival benefit provided that the nodal status is limited to two positive lymph nodes [25].

Another study by Suzuki reported a series of 20 patients, of which 19 underwent bisegmentectomy, $4 b+5$ and one right hepatectomy. EHBDR was performed in $12(60 \%)$ of cases. Perineural invasion was reported as an independent prognostic factor and was closely related with extension of the disease to the neck and cystic duct of the GB. Partial hepatectomy, EH$\mathrm{BDR}$, and regional lymphadenectomy were proposed as procedures of choice for pT2 tumors. EHBDR can be withheld in cases the tumor is limited in the fundus and body [26].

EHBDR appears to have little benefit in the presence of nodal disease. Yokomizo and colleagues reported a case series of 94 patients with pT2 tumors in order to determine the impact of EHBDR on long-term oncological outcome. Patients with pN0 status had a 5-year survival rate of $87.1 \%$, dropping to $55.7 \%$ in those with pN1. Patients with pN0 status who underwent EHBDR had a 5-year survival rate of $66.7 \%$ and who did not had a survival rate of $81.1 \%$. In patients with $\mathrm{pN} 1$, there was no survival benefit in those who underwent EHBDR. Only lymph node dissection proved to have a positive effect on improving survival [27].

\section{pT3/4 tumors}

Three studies compared oncological outcome in patients with T3N1 tumors with the rest of subgroups of the stage III. Huang and colleagues compared survival rate of 103 patients stratified into the following five groups: in T3N0 $(n=26)$, T1N1 $(\mathrm{n}=13), \mathrm{T} 2 \mathrm{~N} 1(\mathrm{n}=35), \mathrm{T} 3 \mathrm{~N} 1(\mathrm{n}=20)$, and T1-3N2 $(\mathrm{n}=$ 9) and found the survival rate for these groups was $57.7 \%$, $15.4 \%, 28.6 \%, 5 \%$, and $22.2 \%$, respectively. T3N1 showed the worst prognosis, comparable to stage IVB tumors even after R0 resection. Based on these findings, the authors proposed extensive lymph node dissection in all patients with T3 tumors in order to remove any potential micro-metastasis [28].

Kondo et al reported outcomes in 72 patients with stage IV disease who underwent major procedures with curative intent. Obstructive jaundice was present in $67 \%(48 / 72)$ of the cohort. Postoperative hospital mortality was $19 \%$ (14/72). Of the total 58 patients discharged from hospital, 11 (19\%) survived more than 3 years. Multivariate analysis demonstrated portal vein resection, right hepatectomy on cholestatic liver and male gender to negatively impact on perioperative mortality [29].

Further studies involving patients with stage IV disease were conducted by Lim and colleagues who sought to determine the necessity of HPD in the context of advanced GB cancer. In this retrospective study, R0 was achieved in 17 (74\%) of the 23 patients. Morbidity was $91.3 \%$ and mortality was $13 \%$. Five-year survival was $10 \%$. They proposed that HPD is a useful procedure in achieving clear proximal and distal ductal margins. They defined three indications for GB cancer patients to undergo HPD: cases with direct invasion of the duodenum, pancreas or liver, secondly cases with hilar involvement and peripancreatic lymph node metastases diagnosed intraoperatively, and thirdly a Karnofsky score more than 70 [30].

\section{Incidental GB cancer}

Incidental GB cancer, that is cancer detected once a cholecystectomy has been performed, usually for gallstone disease has been reported to range from $0.2 \%$ [36] to $0.9 \%$ [37]. A study by Fuks and colleagues studied 218 patients with incidental GB cancer: 67 males and 151 females with a median age of 64 years $(31-88)$. After a median time of 48 days, $148(68 \%)$ of patients underwent re-operation. The most common operation was bisegmentectomy $\mathrm{S} 4 \mathrm{~b}+5$. EHBDR was performed in $43 \%$ of the study population (63/143). Morbidity and mortality were $37 \%$ and $3 \%$, respectively across the cohort. R0 was achieved in $97 \%$ of patients (143/148). There was significant increase of postoperative complications in the EHBDR group $(60 \%)$ compared with the EHBDNR group (23\%). Re-opera- 
tion increased survival of patients with $\mathrm{T} 2$ and $\mathrm{T} 3$ tumors [31]. Further studies have been carried out by Toyonaga and colleagues involving 73 patients with unapparent GB cancer and a median age of 65 years. Of the total population, 26 patients underwent re-operation, 21 underwent radical intervention (pT2: $\mathrm{n}=18 ; \mathrm{pT} 3: \mathrm{n}=3$ ) and five patients had palliative surgery. Port site recurrence was detected in four patients with pT2 tumors. Between pT2 patients who underwent radical intervention and those who did not, there was no significant survival difference. Prolonged survival was demonstrated in $11 \mathrm{pT} 2$ patients with positive surgical margins at first operation [32].

\section{Discussion}

GB cancer is a rare gastrointestinal tumor with variable incidence rates around the world. Its primary location is also variable within the GB, in $60 \%$ of cases located in the fundus, $30 \%$ in the body and only $10 \%$ in the neck [38]. It is reported that the median survival time for fundic carcinoma is 22.5 months (95\% CI: 5.8 - 39.2), for the body/neck 10.4 months (95\% CI: 7.7 - 13.2) and for cystic duct 15.7 months (95\% CI: 9.0 - 22.5) [13]. In 1951, Farrar reported a case and proposed criteria for definition of the cystic duct carcinoma [39]. According to his criteria, 2.6-3.3\% of biliary tumors are primary cystic duct carcinomas.

There are two worldwide acceptable classifications of GB cancer: the AJCC classification, and the JSBS [40-42]. There are not only discrepancies between the two classifications but even between the editions of the same classification $[28,43]$. The fifth edition of the AJCC and JSBS classifies pN2 similarly [34]. However, there is a discrepancy in N classification between the seventh edition of the AJCC and the JSBS as the former divides $\mathrm{N}$ into two categories, the later into three categories [28]. Fong et al considered the sixth edition no improvement of the fifth, because it did not provide discrimination between stage III and IV [43]. Moreover, Oh and colleagues have determined that the seventh edition was no better at predicting prognosis than the sixth edition, suggesting that the extent of lymph node dissection may affect overall survival and the prognostic ability of the TNM staging [44].

Debate continues to revolve around the AJCC definition of oncologic adequacy of lymphadenectomy specimens as they consider three lymph nodes to be adequate $[45,46]$. In contrary, Japanese studies consider this number to be inadequate $[47,48]$. In a large study based on the Surveillance, Epidemiology and End-Results (SEER) program database has demonstrated that patients with $>5$ excised lymph nodes have a better survival over those patients with 1 - 4 lymph nodes harvested. However, only $3.6 \%$ of the population had more than five (histologically proven) nodes harvested [49]. In addition, Coburn et al in a population-based study showed that only $3 \%$ of patients who underwent lymphadenectomy had more than three lymph nodes excised [50]. Other studies, notably by Ito and colleagues have also demonstrated a survival benefit in harvesting $>6$ lymph nodes, although the median total lymph node count in this study was three, ranging from 0 to 20 [46].

Studies from Japanese institutions have attempted to de- termine the mode of spread of GB cancer in order to delineate preoperative and intraoperative strategy. Wakai et al divided hepatic spread into three modes: direct, portal tract invasion and hepatic metastatic nodules using monoclonal antibodies (D2-40) to immunohistochemically distinguish intrahepatic lymphatic invasion from venous invasion [35].

Further studies by Kokudo et al have attempted to use a combination of TNM image staging and intraoperative lymph nodes biopsies to propose specific strategies in the surgical approach for each stage of GB cancer. The weaknesses of this approach were the low diagnostic accuracy rate for $\mathrm{T}$ and $\mathrm{N}$ images especially in early $\mathrm{T} 1$ and $\mathrm{T} 2$. The diagnostic accuracy of their approach for T stage overall was 53\% (95\% CI: 47 $61 \%$ ). This dropped to $34 \%$ and $37 \%$ for $\mathrm{T} 1$ and $\mathrm{T} 2$, respectively. Preoperative $\mathrm{N}$ staging had an even lower diagnostic accuracy, $25 \%$ across all $\mathrm{N}$ stages (95\% CI: $12-37 \%)$. Round lymph nodes with a diameter greater than $10 \mathrm{~mm}$ were considered metastatic. Preoperative investigations of choice were ultrasound, CT scan, endoscopic ultrasound, and angiography. MRCP was considered useful for detecting BDI and hepatic infiltration in T3 or greater tumors [51,52].

In this study, important nodes for lymphatic metastases were considered to be N12c: cystic node, N12b: pericholedochal nodes, and N13a: posterosuperior peripancreatic nodes. A positive interaortocaval node was considered M stage. Specific sample strategy was developed for each stage. Kokudo et al proposed the following indications: if "N12b, N12c and $\mathrm{N} 13 \mathrm{a}$ are negative for metastasis, no further dissection is necessary as the risk of metastases in $\mathrm{pN} 1$ or greater is $0 \%$ in such cases. If $\mathrm{N} 12 \mathrm{~b}$ and $\mathrm{N} 12 \mathrm{c}$ are positive and N13a is negative, complete dissection of $\mathrm{pN} 1$ is adequate because the risk of $\mathrm{pN} 2$ or greater is $0 \%$ in this subgroup. In cases where N13a is positive, $\mathrm{pN} 2$ standard dissection with or without pancreatoduodenectomy should be attempted if metastasis to other $\mathrm{N} 2$ nodes is not extensive. The risk of metastases to other N2 nodes is $33.3 \%$ in such cases. Extended lymph node dissection showed significantly better survival in pN2 cases. In contrast, EHBDR and pancreatoduodenectomy had no positive impact on survival [51].

Both western and Asian biliary centers agree that simple cholecystectomy is the adequate operation for T1a tumors [20, $53,54]$. If the endoscopic ultrasound and intraoperative biopsy confirm the diagnosis of $\mathrm{T} 1 \mathrm{~b}$ tumor, then cholecystectomy and HDL dissection without EHBDR is recommended [20].

In $\mathrm{T} 2$, the potential benefit of radical excision in the presence of a variety of pathological factors such as hepatic infiltration, perineural invasion, extend and number of lymph nodes involved and depth of subserosal invasion have been investigated [21-27]. There is some evidence to suggest that EHBDR and partial hepatectomy may be beneficial to patients with subserosal invasion of more than $2 \mathrm{~mm}$ [21]. However, in cases with more than two lymph nodes affected, radical interventions have not been proven to have any positive impact on loco-regional recurrence and overall survival [6]. Moreover, perineural invasion which has been identified by the majority of these studies to be the absolute indication for radical intervention is impossible to diagnose preoperatively [21-27].

Management of T2 tumors appears problematic for clinicians. In a study by Wright and colleagues, it was found that 
the majority of the patients with T2 tumors in the USA were not managed according to national recommendations [54]. Furthermore, Jensen et al reported that only $4.5 \%$ of $\mathrm{T} 1 \mathrm{~b}$ and $5.6 \%$ of $\mathrm{T} 2$ tumors underwent adequate resection [53]. In addition, a French paper reported that re-resection bisegmentectomy $4 \mathrm{~b}+5$ and lymph node dissection without EHBDR significantly increased survival rate of patients with T2 and T3 incidental tumors [31].

For patients with T3/T4 tumors, radical operations appear to be of questionable benefit. Several studies have demonstrated no real significant increase in overall survival and only a small number of patients survived more than 3 years and therefore the practice is best avoided in all but select group of patients [28-30]. Japanese surgeons propose EHBDR in APBDJ with choledochal dilatation. There is debate whether to resect EHBD in cases with APBDJ without dilatation [34].

This review has sought to determine when it is appropriate to undertake radical surgery in the form of EHBDR in the context of GB cancer. It does however have some limitations mainly that the majority of the studies are retrospective case series or other observational studies, raising the possibility of case selection, non-publication and selective reporting bias. Good quality, multi-center randomized control trial in this area of research is desperately needed. To make matters more complicated, there is no real consensus on how to classify GB cancers. Both the AJCC and TNM classifications disagree with each other in terms of definitions and classifications and in some cases, with themselves from one edition to another.

\section{Conclusions}

The main finding of this review is that EHBDR is not preventative of loco-regional recurrence but can be curative in selected cases. Radical cholecystectomy with EHBDR is useful as a standard operation for tumors involving (macroscopically or microscopically) the neck and/or the cystic duct of the GB and in choledochal type APBDJ. In all other cases, the ability to achieve R0 resection, the presence of distant metastases, extent of EHBD involvement, lymph node status and postoperative morbidity should guide the operative strategy.

\section{References}

1. Glenn F, Hays DM. The scope of radical surgery in the treatment of malignant tumors of the extrahepatic biliary tract. Surg Gynecol Obstet. 1954;99(5):529-541.

2. Pang YY. The Brisbane 2000 terminology of liver anatomy and resections. HPB. 2000; 2:333-339. HPB (Oxford). 2002;4(2):99; author reply 99-100.

3. Pack GT, Miller TR, Brasfield RD. Total right hepatic lobectomy for cancer of the gallbladder; report of three cases. Ann Surg. 1955;142(1):6-16.

4. Benson AB, 3rd, Abrams TA, Ben-Josef E, Bloomston PM, Botha JF, Clary BM, Covey A, et al. NCCN clini-cal practice guidelines in oncology: hepatobiliary cancers. J Natl Compr Canc Netw. 2009;7(4):350-391.

5. Shirai Y, Wakai T, Hatakeyama K. Radical lymph node dissection for gallbladder cancer: indications and limitations. Surg Oncol Clin N Am. 2007;16(1):221-232.

6. Shirai Y, Yoshida K, Tsukada K, Muto T, Watanabe H. Radical surgery for gallbladder carcinoma. Long-term results. Ann Surg. 1992;216(5):565-568.

7. Kayahara M, Nagakawa T, Nakagawara H, Kitagawa H, Ohta T. Prognostic factors for gallbladder cancer in Japan. Ann Surg. 2008;248(5):807-814.

8. Manfredi S, Benhamiche AM, Isambert N, Prost P, Jouve JL, Faivre J. Trends in incidence and management of gallbladder carcinoma: a population-based study in France. Cancer. 2000;89(4):757-762.

9. Donohue JH. Present status of the diagnosis and treatment of gallbladder carcinoma. J Hepatobiliary Pancreat Surg. 2001;8(6):530-534.

10. He XD, Li JJ, Liu W, Qu Q, Hong T, Xu XQ, Li BL, et al. Surgical procedure determination based on tumor-nodemetastasis staging of gallbladder cancer. World J Gastroenterol. 2015;21(15):4620-4626.

11. Shimizu Y, Ohtsuka M, Ito H, Kimura F, Shimizu H, Togawa A, Yoshidome H, et al. Should the extrahepatic bile duct be resected for locally advanced gallbladder cancer? Surgery. 2004;136(5):1012-1017; discussion 1018.

12. Kaneoka Y, Yamaguchi A, Isogai M, Harada T, Suzuki M. Hepatoduodenal ligament invasion by gallbladder carcinoma: histologic patterns and surgical recommendation. World J Surg. 2003;27(3):260-265.

13. Yokoyama Y, Nishio H, Ebata T, Abe T, Igami T, Oda K, Nimura Y, et al. New classification of cystic duct carcinoma. World J Surg. 2008;32(4):621-626.

14. Nasu Y, Tanaka E, Hirano S, Tsuchikawa T, Kato K, Matsumoto J, Shichinohe T, et al. The prognosis after curative resection of gallbladder cancer with hilar invasion is similar to that of hilar cholangiocarcinoma. J Hepatobiliary Pancreat Sci. 2012;19(3):274-280.

15. Nishio H, Ebata T, Yokoyama Y, Igami T, Sugawara G, Nagino M. Gallbladder cancer involving the extrahe-patic bile duct is worthy of resection. Ann Surg. 2011;253(5):953-960.

16. Agarwal AK, Mandal S, Singh S, Bhojwani R, Sakhuja P, Uppal R. Biliary obstruction in gall bladder cancer is not sine qua non of inoperability. Ann Surg Oncol. 2007;14(10):2831-2837.

17. Pandey D, Garg PK, Manjunath NM, Sharma J. ExtraHepatic Bile Duct Resection: an Insight in the Manage-ment of Gallbladder Cancer. J Gastrointest Cancer. 2015;46(3):291-296.

18. Araida T, Higuchi R, Hamano M, Kodera Y, Takeshita N, Ota T, Yoshikawa T, et al. Should the extrahepatic bile duct be resected or preserved in R0 radical surgery for advanced gallbladder carcinoma? Results of a Japanese Society of Biliary Surgery Survey: a multicenter study. Surg Today. 2009;39(9):770-779.

19. Choi SB, Han HJ, Kim WB, Song TJ, Suh SO, Choi SY. Surgical strategy for T2 and T3 gallbladder cancer: is extrahepatic bile duct resection always necessary? Langenbecks Arch Surg. 2013;398(8):1137-1144.

20. You DD, Lee HG, Paik KY, Heo JS, Choi SH, Choi DW. What is an adequate extent of resection for $\mathrm{T} 1$ gallbladder 
cancers? Ann Surg. 2008;247(5):835-838.

21. Wakai T, Shirai Y, Yokoyama N, Ajioka Y, Watanabe H, Hatakeyama K. Depth of subserosal invasion pre-dicts long-term survival after resection in patients with T2 gallbladder carcinoma. Ann Surg Oncol. 2003;10(4):447454.

22. Kohya N, Kitahara K, Miyazaki K. Rational therapeutic strategy for T2 gallbladder carcinoma based on tumor spread. World J Gastroenterol. 2010;16(28):3567-3572.

23. Gwark SC, Hwang S, Kim KH, Lee YJ, Park KM, Ahn CS, Moon DB, et al. Extent of resection for T2N0 gallbladder carcinoma regarding concurrent extrahepatic bile duct resection. Korean J Hepatobiliary Pancreat Surg. 2012;16(4):142-146.

24. Sakamoto Y, Kosuge T, Shimada K, Sano T, Hibi T, Yamamoto J, Takayama T, et al. Clinical significance of extrahepatic bile duct resection for advanced gallbladder cancer. J Surg Oncol. 2006;94(4):298-306.

25. Shirai Y, Sakata J, Wakai T, Ohashi T, Hatakeyama K. "Extended" radical cholecystectomy for gallbladder cancer: long-term outcomes, indications and limitations. World J Gastroenterol. 2012;18(34):4736-4743.

26. Suzuki S, Yokoi Y, Kurachi K, Inaba K, Ota S, Azuma M, Konno H, et al. Appraisal of surgical treatment for pT2 gallbladder carcinomas. World J Surg. 2004;28(2):160165.

27. Yokomizo H, Yamane T, Hirata T, Hifumi M, Kawaguchi T, Fukuda S. Surgical treatment of pT2 gallbladder carcinoma: a reevaluation of the therapeutic effect of hepatectomy and extrahepatic bile duct resection based on the long-term outcome. Ann Surg Oncol. 2007;14(4):13661373.

28. Hwang KY, Yoon YI, Hwang S, Ha TY, Ahn CS, Kim KH, Moon DB, et al. Survival analysis following re-section of AJCC stage III gallbladder carcinoma based on different combinations of T and $\mathrm{N}$ stages. Korean J Hepato-biliary Pancreat Surg. 2015;19(1):11-16.

29. Kondo S, Nimura Y, Kamiya J, Nagino M, Kanai M, Uesaka K, Yuasa N, et al. Factors influencing postopera-tive hospital mortality and long-term survival after radical resection for stage IV gallbladder carcinoma. World J Surg. 2003;27(3):272-277.

30. Lim CS, Jang JY, Lee SE, Kang MJ, Kim SW. Reappraisal of hepatopancreatoduodenectomy as a treatment modality for bile duct and gallbladder cancer. J Gastrointest Surg. 2012;16(5):1012-1018.

31. Fuks D, Regimbeau JM, Le Treut YP, Bachellier P, Raventos A, Pruvot FR, Chiche L, et al. Incidental gallbladder cancer by the AFC-GBC-2009 Study Group. World J Surg. 2011;35(8):1887-1897.

32. Toyonaga T, Chijiiwa K, Nakano K, Noshiro H, Yamaguchi K, Sada M, Terasaka R, et al. Completion radical surgery after cholecystectomy for accidentally undiagnosed gallbladder carcinoma. World J Surg. 2003;27(3):266271.

33. Yagi H, Shimazu M, Kawachi S, Tanabe M, Aiura K, Wakabayashi G, et al. Retrospective analysis of outcome in 63 gallbladder carcinoma patients after radical resection. J Hepatobiliary Pancreat Surg. 2006;13:530-536
34. Tashiro S, Imaizumi T, Ohkawa H, Okada A, Katoh T, Kawaharada Y, Shimada H, et al. Pancreaticobiliary maljunction: retrospective and nationwide survey in Japan. J Hepatobiliary Pancreat Surg. 2003;10(5):345-351.

35. Wakai T, Shirai Y, Sakata J, Nagahashi M, Ajioka Y, Hatakeyama K. Mode of hepatic spread from gallbladder carcinoma: an immunohistochemical analysis of 42 hepatectomized specimens. Am J Surg Pathol. 2010;34(1):6574.

36. Pitt SC, Jin LX, Hall BL, Strasberg SM, Pitt HA. Incidental gallbladder cancer at cholecystectomy: when should the surgeon be suspicious? Ann Surg. 2014;260(1):128133.

37. Shimizu T, Arima Y, Yokomuro S, Yoshida H, Mamada $\mathrm{Y}$, Nomura T, Taniai N, et al. Incidental gallbladder cancer diagnosed during and after laparoscopic cholecystectomy. J Nippon Med Sch. 2006;73(3):136-140.

38. Albores-Saavedra J, Henson DE, Klimstra DS. Tumors of the gallbladder, extrahepatic bile ducts, and ampulla of Vater. Washington D.C.: Armed Forces Institute of Pathology; 2000.

39. Farrar DA. Carcinoma of the cystic duct. Br J Surg. 1951;39(154):183-185.

40. Edge SB, Compton CC. The American Joint Committee on Cancer: the 7th edition of the AJCC cancer staging manual and the future of TNM. Ann Surg Oncol. 2010;17(6):1471-1474.

41. Hermanek P, Sobin LH, editors. TNM Classification of Malignant Tumours. [Online] Berlin, Heidelberg: Springer Berlin Heidelberg; 1987.

42. Japanese Society of Biliary Surgery. General rules for surgical and pathological studies on cancer of the biliary tract. 5th ed. Kanehara (ed.) Tokyo.

43. Fong Y, Wagman L, Gonen M, Crawford J, Reed W, Swanson R, Pan C, et al. Evidence-based gallbladder cancer staging: changing cancer staging by analysis of data from the National Cancer Database. Ann Surg. 2006;243(6):767-771; discussion 771-764.

44. Oh TG, Chung MJ, Bang S, Park SW, Chung JB, Song SY, Choi GH, et al. Comparison of the sixth and sev-enth editions of the AJCC TNM classification for gallbladder cancer. J Gastrointest Surg. 2013;17(5):925-930.

45. Greene F, Page D, ID F, A F, CM B, DG H, et al. (eds.) American Joint Committee on Cancer. AJCC Cancer Staging Manual - 6th Edition. New York: Springer-Verlag; 2002.

46. Ito $\mathrm{H}$, Ito $\mathrm{K}$, D'Angelica $\mathrm{M}$, Gonen $\mathrm{M}$, Klimstra $\mathrm{D}$, Allen P, DeMatteo RP, et al. Accurate staging for gallbladder cancer: implications for surgical therapy and pathological assessment. Ann Surg. 2011;254(2):320-325.

47. Endo I, Shimada H, Tanabe M, Fujii Y, Takeda K, Morioka $\mathrm{D}$, Tanaka $\mathrm{K}$, et al. Prognostic significance of the number of positive lymph nodes in gallbladder cancer. $\mathrm{J}$ Gastrointest Surg. 2006;10(7):999-1007.

48. Sakata J, Shirai Y, Wakai T, Ajioka Y, Hatakeyama K. Number of positive lymph nodes independently determines the prognosis after resection in patients with gallbladder carcinoma. Ann Surg Oncol. 2010;17(7):18311840. 
49. Downing SR, Cadogan KA, Ortega G, Oyetunji TA, Siram SM, Chang DC, Ahuja N, et al. Early-stage gallbladder cancer in the Surveillance, Epidemiology, and End Results database: effect of extended surgical resection. Arch Surg. 2011;146(6):734-738.

50. Coburn NG, Cleary SP, Tan JC, Law CH. Surgery for gallbladder cancer: a population-based analysis. J Am Coll Surg. 2008;207(3):371-382.

51. Kokudo N, Makuuchi M, Natori T, Sakamoto Y, Yamamoto J, Seki M, Noie T, et al. Strategies for surgical treatment of gallbladder carcinoma based on information available before resection. Arch Surg. 2003;138(7):741750 ; discussion 750 .
52. Schwartz LH, Black J, Fong Y, Jarnagin W, Blumgart L, Gruen D, Winston C, et al. Gallbladder carcinoma: findings at MR imaging with MR cholangiopancreatography. J Comput Assist Tomogr. 2002;26(3):405-410.

53. Jensen EH, Abraham A, Habermann EB, Al-Refaie WB, Vickers SM, Virnig BA, Tuttle TM. A critical analysis of the surgical management of early-stage gallbladder cancer in the United States. J Gastrointest Surg. 2009;13(4):722727.

54. Wright BE, Lee CC, Iddings DM, Kavanagh M, Bilchik AJ. Management of T2 gallbladder cancer: are prac-tice patterns consistent with national recommendations? Am J Surg. 2007;194(6):820-825; discussion 825-826. 